\title{
Power spectra of quarry blasting works measured in different depths
}

\author{
Zdeněk KALÁB $B^{1,2^{*}}$ and Alexey A. LYUBUSHIN ${ }^{3}$
}

Authors' affiliations and addresses:

${ }^{1}$ Institute of Geonics, Czech Academy of

Sciences, Ukrajinská 1768, 70800 Ostrava-

Poruba, Czech Republic

e-mail: kalab@ugn.cas.cz

${ }^{2}$ VŠB - Technical University of Ostrava, Faculty of Civil Engineering, 17. listopadu 15, 70800 Ostrava-Poruba, Czech Republic

e-mail: kalab@ugn.cas.cz

${ }^{3}$ Schmidt Institute of Physics of the Earth of the Russian Academy of Sciences, Bolshaya Gruzinskaya str., 10-1, Moscow 123242,

Russia

e-mail: lyubushin@yandex.ru

*Correspondence:

Zdeněk Kaláb, Institute of Geonics, Czech Academy of Sciences, Ukrajinská 1768, 70800 Ostrava-Poruba, Czech Republic

Tel.: +420-604245362

e-mail: kalab@ugn.cas.cz

Funding information:

Research program of the Academy of Sciences of the Czech Republic, RVO: 68145535

\section{Acknowledgement:}

The paper was prepared with the financial support of the Research program of the Academy of Sciences of the Czech Republic, RVO: 68145535

How to cite this article:

Kaláb, Z. and Lyubushin, A., A. (2020). Power spectra of quarry blasting works measured in different depths. Acta Montanistica Slovaca, Volume 25 (3), 302-309

DOI:

https://doi.org/10.46544/AMS.v25i3.4

\begin{abstract}
Vibrations generated by quarry blasting are the most intensive manifestation of technical seismicity. Comparative measurements of vibrations from blasting generated in open-pit mines were performed in the Jeroným Mine near Čistá (Czech Republic). A detailed evaluation of vibrations on underground spaces is very important here because this mine is a significant heritage site of medieval tin mining. The distance between the nearest feldspathic quarry named Krásno and the Jeroným Mine is $4.7 \mathrm{~km}$ east, Vítkov quarries (granite) is located north in the distance of $6.3 \mathrm{~km}$. Maximum values from the nearest quarry Krásno are usually within the range of $10^{-3}-10^{-2} \mathrm{~mm} \cdot \mathrm{s}^{-1}$. Prevailing frequency range of recorded waves is $1-6 \mathrm{~Hz}$ for both quarries.

To qualify seismic loading of mine, one seismic station was located on the surface, the second one in the mine at a depth of about $30 \mathrm{~m}$. Power spectra could be used for distinguishing, but the difference in spectra shapes is rather evident. Especially the difference is most explicit for the frequency range $70-100 \mathrm{~Hz}$ between power spectra of surface and underground records. Fitted trends were calculated for the mentioned frequency range of power spectra. Spectral time-frequency diagrams were also defined.
\end{abstract}

\section{Keywords}

Seismic measurement, power spectrum, spectral time-frequency diagram, surface and underground measurements, medieval mine 


\section{Introduction}

Vibrations of blasting works are studied in detail by a number of authors from various points of view, especially physical and chemical properties of explosives, processes in the source of blasting, seismic wave propagation through rock mass, influence on the surface and other building objects, numerical modelling of vibration manifestations or its structural elements (for example, Pijush, 2009; Ainalis et al., 2017; Kaláb and Štemon, 2017; Kaláb, 2018).

Explosion generates short, intense impulse. Its spectrum is continuous and contains frequencies from lower values to very high values - usually 1 to $300 \mathrm{~Hz}$. An empirical relationship, the so-called Langefors relationship (for example, Bongiovanni et al., 1991; Kaláb et al., 2013) is used to determine maximum vibration velocity values in the distant zone. This relationship, which is mainly used to assess the seismic effect of blasting operations in quarries, is often given in the form

$$
V_{\max }=K \cdot Q^{m} \cdot 1^{-n} \text {, }
$$

where $V_{\max }$ - maximum vibration velocity $\left(\mathrm{mm} \cdot \mathrm{s}^{-1}\right), Q$ - the weight of the charge $(\mathrm{kg}), l$ - distance from the centre of charge (m) and, $K, m$ and $n$ are empirical parameters. The graphs are constructed either as a relationship of the maximum vibration velocity $V_{\max }$ on the distance $l$ or, on the so-called reduced distance $l_{\text {red }}$, which is the ratio of the distance $l$ and the square root of the charge weight $Q\left(l_{\text {red }}=1 / Q^{0.5}\right)$. This relationship may be very well defined, but may have a very low correlation for complicated local geology (for example, Pijush, 2009; Pandula et al., 2007; Kondela and Pandula, 2012). Before the measurement of blasting vibration, it is necessary to make a qualified estimation of both the maximum vibration values (usually velocity or acceleration) and the frequency range of the measured vibration. Special attention is necessary to take into account if the evaluated structure is a historical monument or underground spaces.

The contribution of this paper is based on demonstration of processing of seismic record of blasting in the frequency domain. Two identical seismic apparatuses were used at the chosen site in the medieval Jeroným Mine. One seismic station was located in the building on the surface, the other at a depth of about 30 meters below the surface. This study describes the use of spectral analysis of seismic records. Wave patterns of blasting from surface quarries were used; the distance between the nearest Krásno quarry (feldspar mining) and the Jeroným Mine is $4.7 \mathrm{~km}$ to the east, the Vítkov granite quarry is located at a distance of $6.3 \mathrm{~km}$ to the north. The maximum values of nearer Krásno quarry are usually in the range of $10^{-3}-10^{-2} \mathrm{~mm} \cdot \mathrm{s}^{-1}$ (values are not very significant for stability evaluation). The predominant frequency range of recorded vibrations is $1-6 \mathrm{~Hz}$ for both quarries. Power spectra are introduced, and spectral time-frequency diagrams are calculated.

\section{Research of the amplitude versus depth relationship}

A most important article on the relationship between the maximum amplitude and depth was published by Chinese researchers $\mathrm{Hu}$ and Xie in 2004. The ratio of the amplitudes in the observed depth (underground) and the surface is used for the examination of changes in the value of vibration relative to depth (underground amplitude/surface amplitude). The value of the maximum surface amplitude is greater than in the underground. Further, the surface records are much more frequent than from underground; therefore, the values for the underground can be determined using statistical regression curves. The Dowding's and Rozen's study (1978 in Varnusfaderani et al., 2015) divides the damage to underground structures into three categories according to the effects of the earthquake: damage caused by vibrations, damage caused by faults and damage caused by disturbances due to the earthquake, for example, soil liquefaction or landslides. Varnusfaderani et al. (2015) also pay attention to the source mechanism of earthquakes. Manifestations of underground seismic activity can be divided into two categories: vibration - changes in stress-strain conditions and, loss of stability - soil liquefaction, fault in the rock massif, landslides. The example is shown in Fig. 1, in order to illustrate the difference of variation in different sites, the same level of magnitude (moderate magnitude) in the two kinds of sites is selected. From the two simulated curves we can see that, on average, the peak ground velocity declines more rapidly in soil/rock site than that in soil site for moderate earthquakes. 


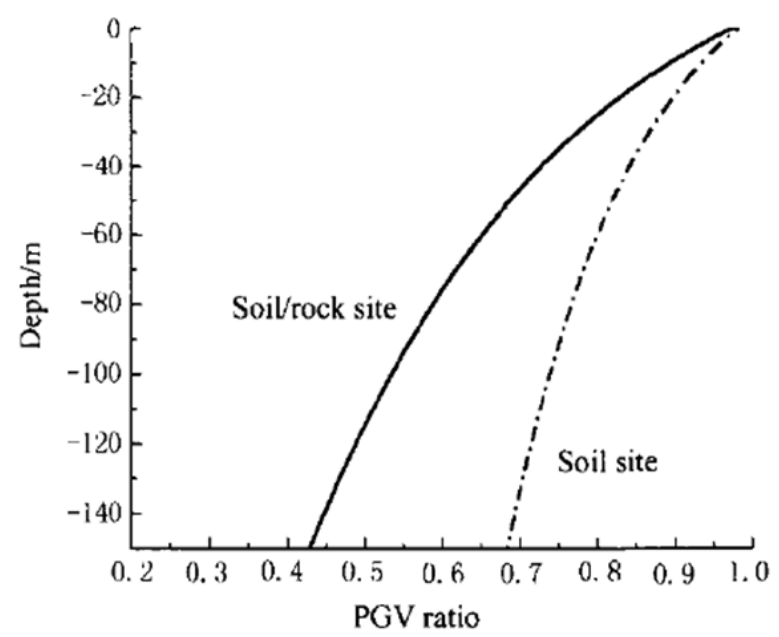

Fig. 1 The comparison of PGV ratios in different sites (Hu and Xie, 2004)

Based on the results of $\mathrm{Hu}$ and Xie (2004), it was drawn general conclusions (these two remarks to the solved topic of the paper):

- In general, the earthquake amplitude decreases with depth, and the declining extent is more dramatic in shallower layers than that in deeper ones.

- The reduction of amplitude with depth is affected by the magnitude and site geology. In general, for soil site, the declining extent decreases with the increment of magnitude as well as the amplitude.

Parametric studies were carried out to investigate the influence of the desired variables on the dynamic behaviour of an underground structure while earthquake loading (Serati and Moosavi, 2010). To perform a sensibility analysis of a particular parameter, a suitable model based on all important concepts of dynamic analysis was created.

\section{The Jeroným Mine near Čistá}

The Jeroným Mine near Čistá, Sokolov District, Czech Republic, is an important heritage documenting medieval tin mining (for example, Tomíček, 2011). The Jeroným Mine represents a complex structure of galleries, shafts and chambers on at least three horizontal levels whereas the lowest level (about $50 \mathrm{~m}$ below the surface) is permanently flooded and its scope is unknown. Nowadays, selected spaces of the mine are opened for the public in the form of a mining museum. The stability of the underground spaces, the parts of which are more than 400 years old (Fig. 2), is the priority both in light of preservation of the unique spaces for the generations to come and in light of safety of people attending the mine. For many years, when the complex of mine workings was inaccessible, the underground spaces were subjected to spontaneous devastation and weathering. Therefore it is necessary to evaluate the stability of the whole complex and to determine the most critical places in the mine (for example, Kaláb et al., 2010; Telesca et al., 2011; Kaláb and Lednická, 2011; Lyubushin et al., 2012).

The first steps towards preserving the Jeroným Mine were taken in the 1990s. In 2000, detailed studies of access to this historic mine were made, and remediation work began. During the work, attention is paid not only to securing mine workings but also protection of own monuments from damage. The purpose of the existing geomechanical and seismological monitoring is to assess the geomechanical stability, control the impact of mining work on historic mining areas and the impact of traffic from the road passing over the mine; some areas are shallow below the ground (for example, Kaláb, 2003; Kaláb and Lednická, 2016; Lednická and Kaláb, 2013, 2016).

The assessment of the seismic loading of the historical spaces of the Jeroným Mine is based on seismological monitoring with the triggered data recording. The most significant seismic load on the Jeroným Mine during the monitoring period was seismic swarms with foci in the vicinity of Nový Kostel village. The seismic load of the historical spaces of the Jeroným Mine makes it possible not only to continuously monitor the possible negative impact of vibrations on the historical part of the mine but above all to correctly determine the critical load values during reconstruction work in the mine and its surroundings (Lednická and Kaláb, 2016a). 

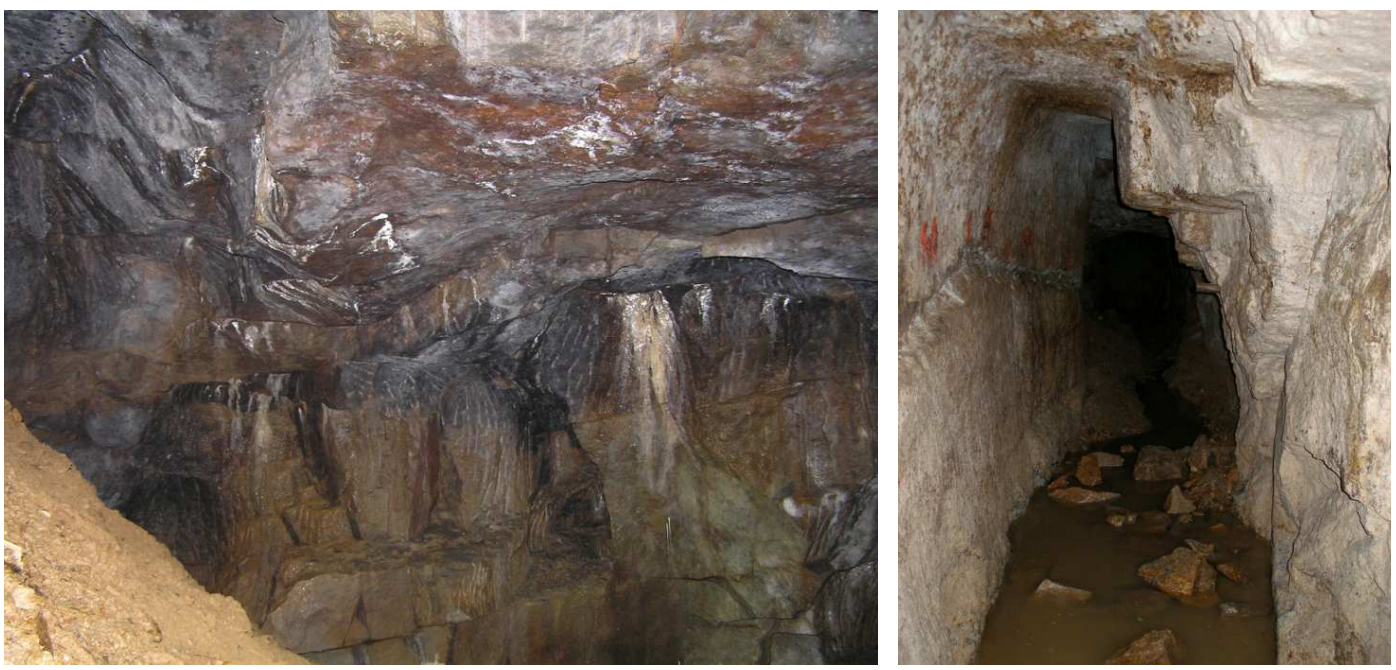

Fig. 2 Photos of manual mining and setting fire in the medieval Jeroným Mine (photo: Lednická)

Maximum measured values of component vibration velocity for individual sources are represented depending on the prevailing frequency range of measured signals (Fig. 3, Kaláb et al., 2015). For natural earthquakes from the Nový Kostel focal zone, component vibration velocities for a maximal expected earthquake with $\mathrm{ML}=5.0$ is predicted, which is also included. The maximum value of traffic in this figure corresponds to the vibration effect measured in shallow underground spaces directly under the road. Study of vibration effect of near earthquakes at different depths in a shallow medieval mine was published by (Lednická and Kaláb, 2016).

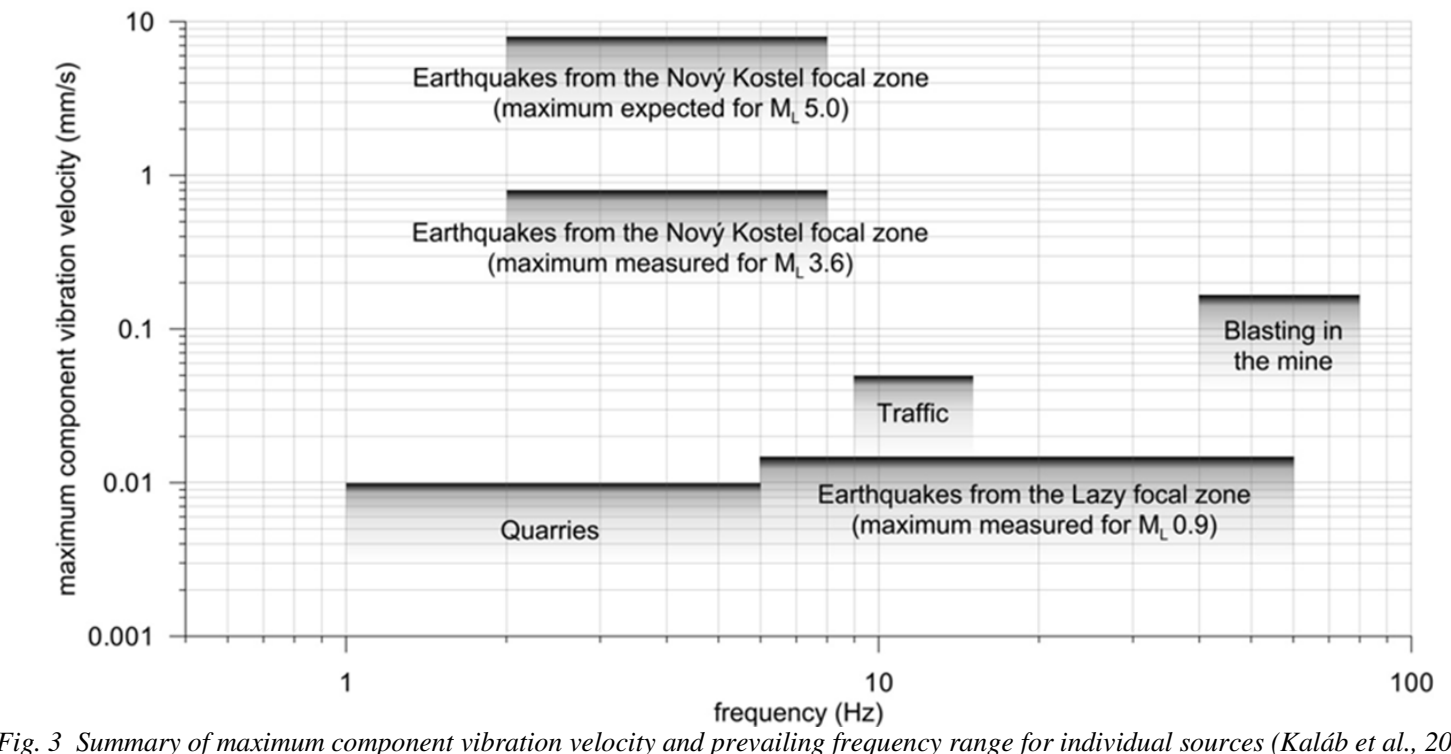

Comparative measurements of blasting vibration and the interpretation

The BR32 seismic apparatuses and Lennartz Le3D-1s sensors with a natural frequency of $1 \mathrm{~Hz}$ and a range of up to $100 \mathrm{~Hz}$ were used in the test described below. The sampling frequency of the digital signal was set to $250 \mathrm{~Hz}, \mathrm{LSB}=1.4552 * 10^{-9} \mathrm{~mm} \cdot \mathrm{s}^{-1}$. The equipment marked B41 was located on the lowest floor of the administrative building of the Jeroným Mine, the second one marked B48 had a sensor located at a depth of about $30 \mathrm{~m}$ below the surface in underground space. To present the effect of sensor location at different points (almost in vertical position), records of two blasting operations from nearby surface quarries were chosen (Vítkov, Krásno - see above). Studies dealing with detailed analysis of seismic records are known from a number of articles and books, e.g., Udías and Buforn, 2017. In this paper, we present the results of the calculation of power spectra and spectral time-frequency diagrams. A detailed description of the data processing methodology is given in the articles (Lyubushin, 2001, 2007; Lyubushin et al., 2013, 2014). 
As mentioned above, four three-component wave patterns were used for the presentation of spectral analyses. Power spectra (Fourier transform) of the recordings are presented on Fig. 4. The first two columns of spectra S (f) from the left represent the result from the underground station (B48), the other two columns of spectra are from the surface station (B41); individual components top-down in sequence vertical component Z, north-south horizontal component $\mathrm{N}$ and east-west horizontal component $\mathrm{E}$.

$180227120542 B 48$
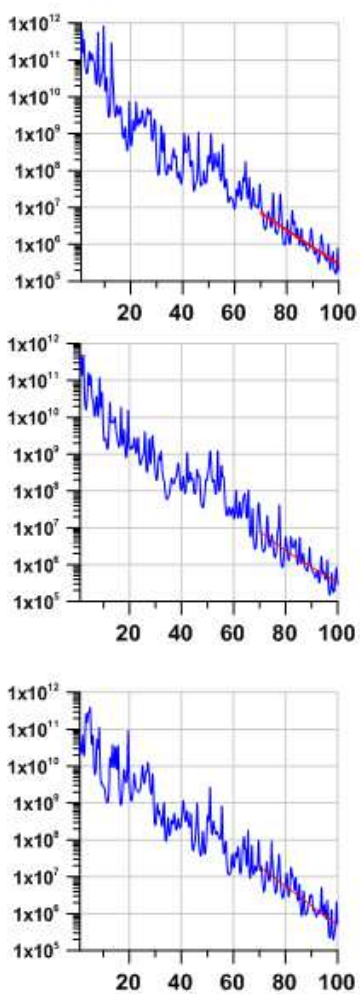

$180323070000 \mathrm{~B} 48$
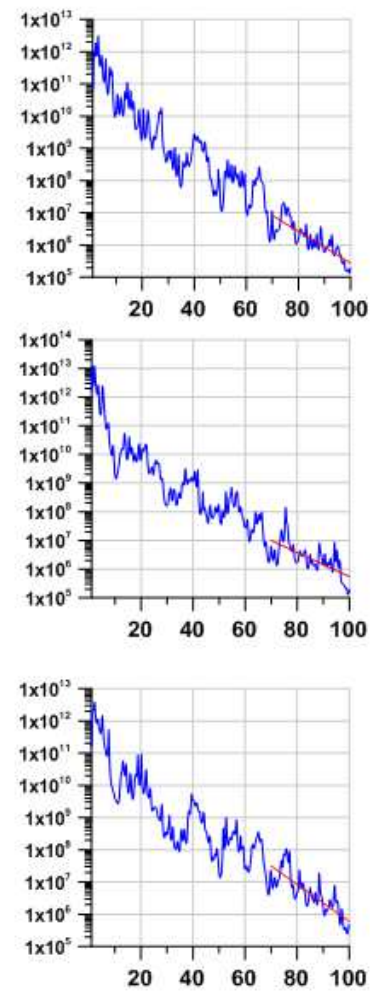

$180227120545 B 41$
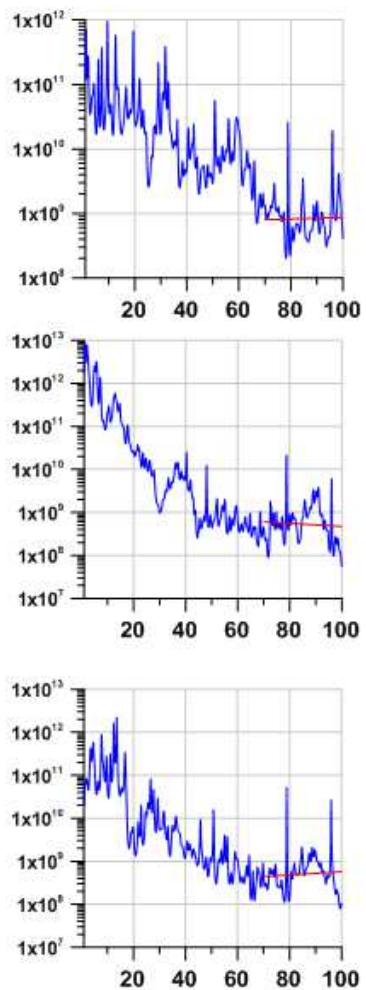

$180323070004 B 41$

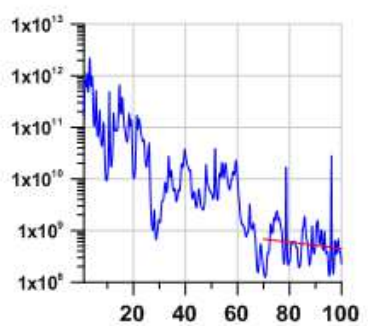

Z

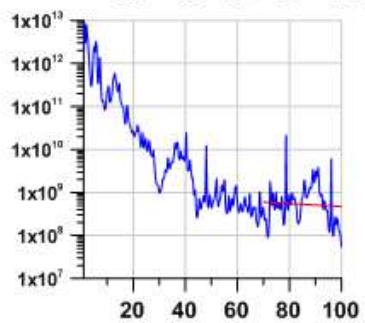

$\mathbf{N}$

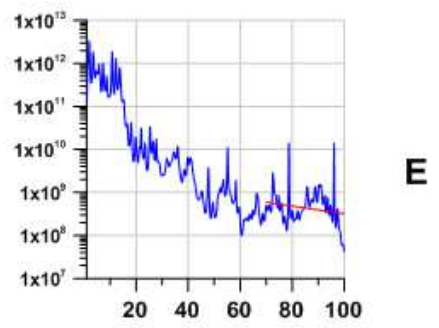

Frequency, $\mathrm{Hz}$

Fig. 4 Power spectra (Fourier transform) of blasting records from underground (B48) and surface (B41) seismic stations, on the horizontal axis, is the frequency in $\mathrm{Hz}$ (for details see text)

The red line shows the trend of the spectral line in the range of $70-100 \mathrm{~Hz}$ in the form of $\log (\mathrm{S}(\mathrm{f})) \sim \mathrm{f}$. It is absolutely evident that the character of the spectra from the surface and mining station is significantly different:

- The range of values $S$ (f) is several orders higher for the records from the mining station;

- The variability of the spectral line is significantly lower for the recording from the mining station;

- The trend of the spectral line in the range of $70-100 \mathrm{~Hz}$ is significantly different. Red lines in the spectra fitted this trend of $\log (\mathrm{S}(\mathrm{f})) \sim \mathrm{f}$. To compare the trends, they are almost constant for surface records; however, line relations with negative angular coefficient are well defined for mining records. The same character is possible to detect for all components.

The above-mentioned differences in the characteristics of the spectra, among other things, clearly enable the distinction of spectra/records taken on the surface and in the underground.

The result from the calculation of time-frequency spectra is again presented on the same records (Fig. 5). The result is based on the calculation of the development of the logarithm of the spectrum with a right-hand end of moving time window of 250 samples (i.e. $1 \mathrm{~s}$ ) with a step of 25 samples (i. e. $0.1 \mathrm{~s}$ ). The relative time is on the horizontal axis, the colour scale decimal logarithm of the power spectrum. This result also shows a clear difference between the time-frequency structure of the spectra for mining (Fig. 5a) and surface (Fig. 5b) station records.

The relative time is on the horizontal axis, the seismic effect of blasting begins in time about $5 \mathrm{~s}$ of the records as a sharp change of the spectral function. Possibility to evaluate the dynamic structure of the signals is the main findings of this method. Vibration effect recorded on the underground station is much longer than on the surface one. These calculations show significant vibrations on the underground station about 15 - 20 s; main frequency range below $10 \mathrm{~Hz}$ is more extensive. 

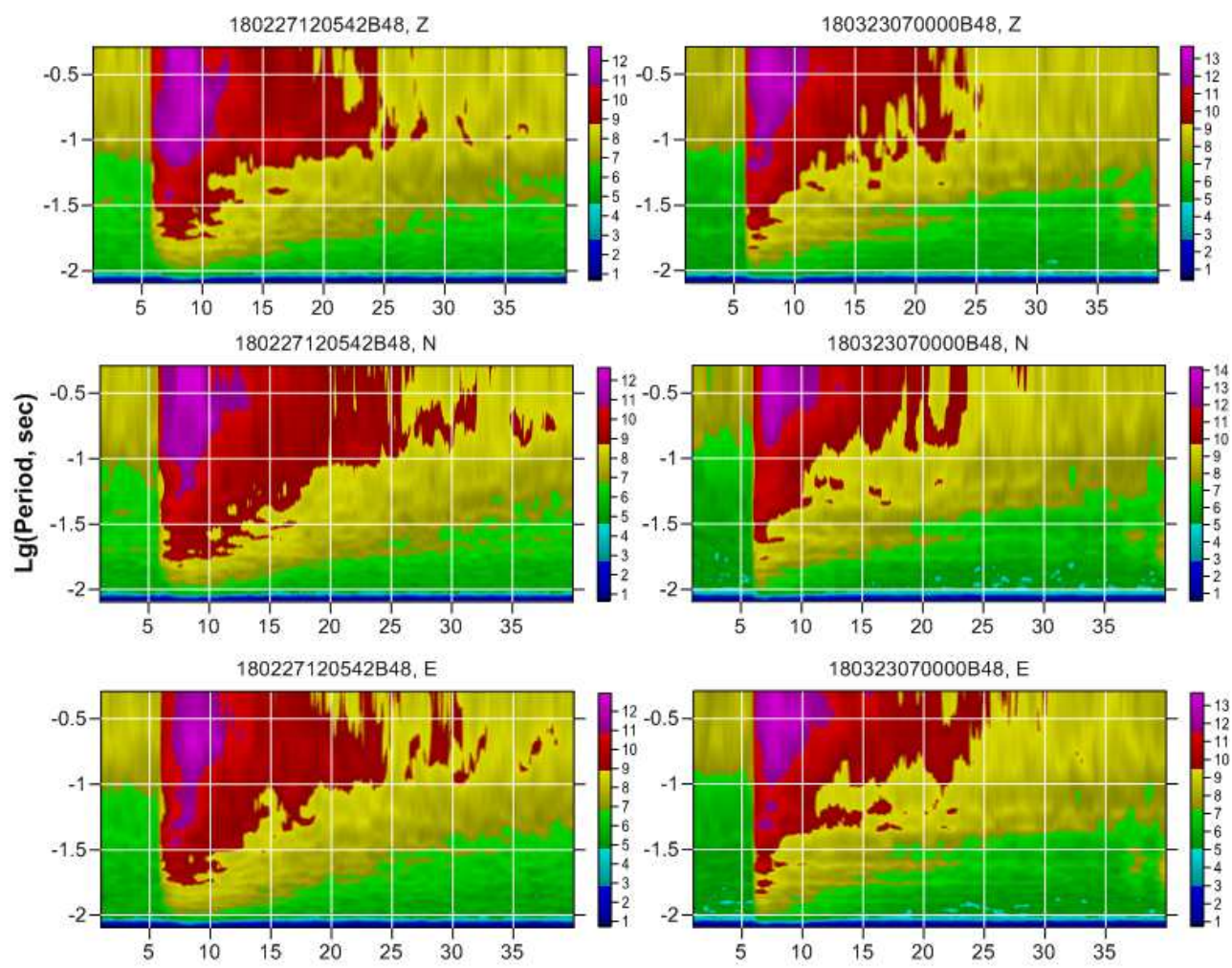

Fig. 5 a Evaluation of the logarithm of power spectra within moving time window of the length 250 samples taken with mutual shift 25 samples - underground station B48; on the horizontal axis is the relative time in s (for details see text)
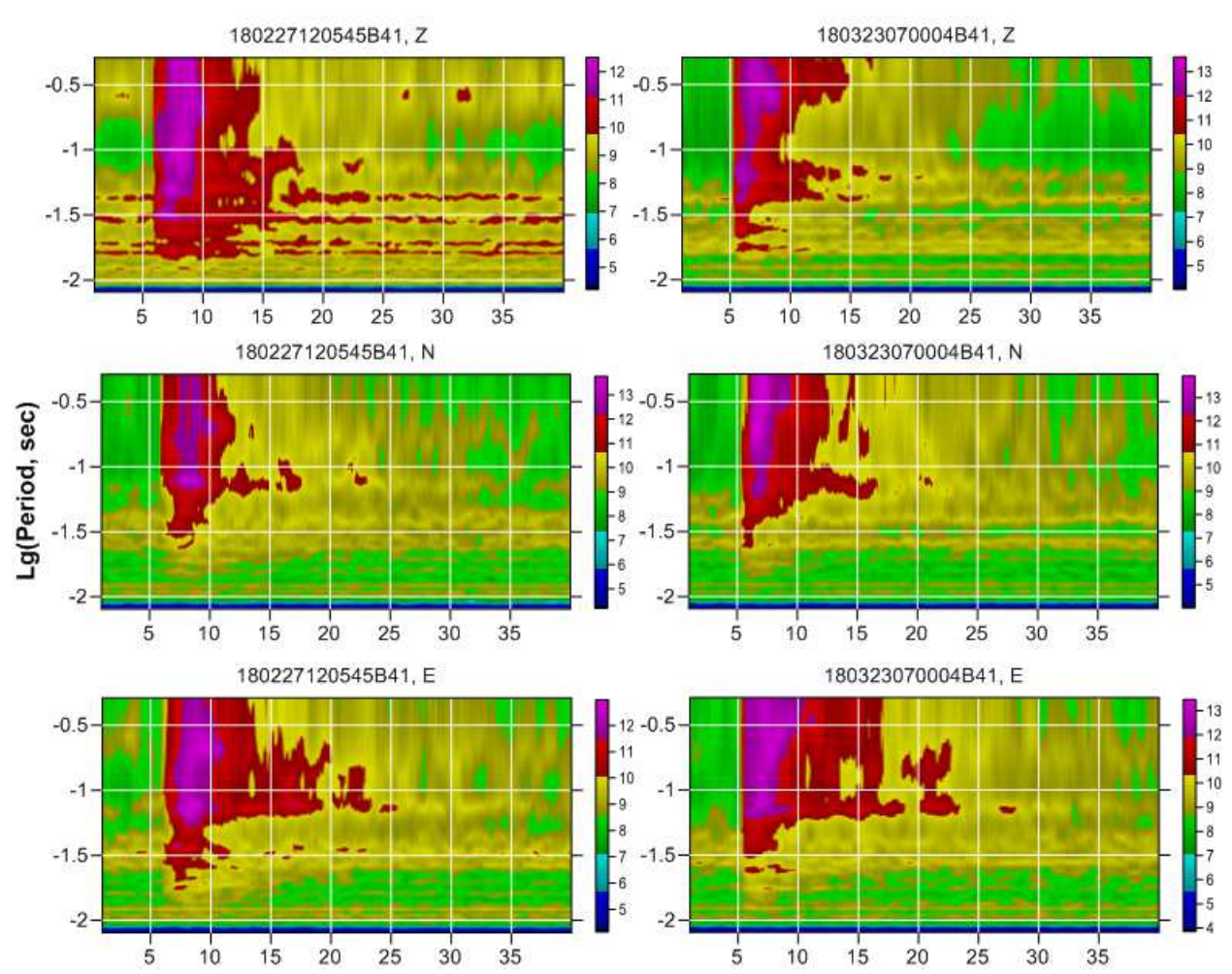

Fig. 5 b Evaluation of the logarithm of power spectra within moving time window of the length 250 samples taken with mutual shift 25 samples - surface station B41; on the horizontal axis is the relative time in $s$ (for details see text) 


\section{Discussion of results and conclusion}

Evaluation of vibration effect in underground spaces, like tunnels, mines or caves, are often discussed. Numerical models and first of all experimental measurements are base for these discussions. Generally, the peak values of vibrations decrease with depth. This decline is usually faster in shallower layers as opposed to deeper parts. The reduction of amplitude depending on the depth is influenced by the value of vibrations and local geological pattern. Principal conclusions developed in the study of Pratt et al. (1978) were:

- There are very few data on damage in the subsurface due to earthquakes. This fact itself attests to the lessened effect of earthquakes in the subsurface because mines exist in areas where strong earthquakes have done extensive surface damage.

- More damage is reported in shallow tunnels near the surface than in deep mines.

- In mines and tunnels, large displacements occur primarily along pre-existing faults and fractures or at the surface entrance to these facilities.

To have more information for numerical studies, detailed analyses of seismograms are performed in the frequency domain. We used two identical seismic instrumentations for measurement of vibration effect on the surface (B41) and in underground space (B48). The shape of power spectra could be used for distinguishing. Especially the difference is most explicit for the frequency range 70-100 Hz between power spectra of B48 and B41 records. The difference in power spectra shapes and in the time-frequency structure of records is rather evident. This result also contributes to better knowledge of frequency content of surface and underground record that is input information for numerical modelling of vibration loading of given structure.

The presented calculations show a significant contribution of two methods of spectral analysis of digital records to obtain new information about the signal, especially the frequency structure of the signal, i.e. clear or "invisible" harmonic components of the signal or the dynamic structure of the signal.

\section{References}

Ainalis, D., Kaufmann, O., Tshibangu, J.P., Verlinden, O. and Kouroussis, G. (2017). Modelling the source of blasting for the numerical simulation of blast-induced ground vibrations: A review. Rock Mech Rock Eng, Vol. 50, p. 171-193. DOI: 10.1007/s00603-016-1101-2

Bongiovanni, G., Gorelli, V., Rienzo, G. and Rinaldis, D. (1991). Experimental studies of vibrations caused by blasting for tunnel excavations. In: Earthquake, Blast and Impacts: Measurements and Effects of Vibration. Elsevier Applied Science, p. 201-210.

$\mathrm{Hu}$, J. and Xie, L. (2004). Variation of earthquake ground motion with depth. Acta Seismologica Sinica, Vol. 18, No. 1, p. 72-81, DOI: 1000-9116(2004)01-0072-10

Kaláb, Z. (2003). Evaluation of seismic load of the medieval mine Jeroným, Czech Republic. Acta Montanistica Slovaca, Vol. 8 (2003), No.1, Košice, Slovakia, p. 36-41. /in Czech/ https://actamont.tuke.sk/pdf/2003/n1/7kalab.pdf

Kaláb, Z. (2018). Influence of vibrations on structures. Acta Montanistica Slovaca, Vol. 23 (2018), No. 3., p. 293-311. https://actamont.tuke.sk/pdf/2018/n3/6kalab.pdf

Kaláb, Z. and Lednická, M. (2011). Seismic loading of medieval Jeroným Mine during West Bohemia swarm in 2008. In: Idziak, A.F. and Dubiel, R. - editors: Geophysics in Mining and Environmental Protection. Ser. Geoplanet: Earth and Planetary Science, Vol. 2, p. 21-30. DOI: 10.1007/978-3-642-19097-1_3

Kaláb, Z. and Lednická, M. (2016). Long-term geomechanical observation in the Jeroným Mine. Acta Geophysica, Vol. 64, No. 5, p. 1513-1524. DOI: 10.1515/acgeo-2016-0054

Kaláb, Z. and Štemon, P. (2017). Influence of seismic events on shallow geotechnical structures. Acta Montanistica Slovaca, Vol. 22 (2017), No. 4, p. 412-421. https://actamont.tuke.sk/pdf/2017/n4/9kalab.pdf

Kaláb, Z., Lednická, M ., Knejzlík, J. and Telesca, L. (2010). First results from long-term monitoring of distance using a laser distance meter in shallow medieval mine. Acta Geodyn. Geomater., Vol. 7, No. 4 (160), p. 469-475. https://www.irsm.cas.cz/materialy/acta_content/2010_04/8_Kalab.pdf

Kaláb, Z., Pandula, B., Stolárik, M. and Kondela, J. (2013). Examples of law of seismic wave attenuation.

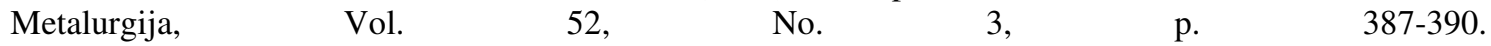
http://public.carnet.hr/metalurg/Metalurgija/2013_vol_52/No_3/MET_52_3_387-390_Kalab.pdf

Kaláb, Z., Lednická, M., Kaláb, T. and Knejzlík, J. (2015). Evaluation of vibration effect in shalow mine caused by natural and technical seismicity. In: 15th International Multidisciplinary Scientific Geoconference SGEM 2015, Albena, Bulgaria. Conference proceedings, Science and Technologies in Geology, Exploration and Mining, Vol. III, p. 855 - 862. DOI: 10.5593/sgem2015B13 
Kondela, J. and Pandula, B. (2012). Timing of quarry blasts and its impact on seismic effects. Acta Geodyn.

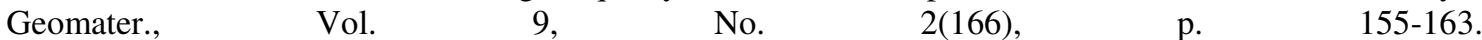
https://www.irsm.cas.cz/materialy/acta_content/2012_02/5_Kondela-Pandula.pdf

Lednická, M. and Kaláb, Z. (2013). Vibration effect of earthquakes in abandoned medieval mine. Acta Geod Geophys., Vol. 48, No. 3, p. 221-234. DOI 10.1007/s40328-013-0018-4

Lednická, M. and Kaláb, Z. (2016). Vibration effect of near earthquakes at different depths in a shallow medieval mine. Acta Geophysica, Vol. 64, No. 6, p. 2244-2263. DOI: 10.1515/acgeo-2016-0085

Lednická, M. and Kaláb, Z. (2016a). Determination of granite rock massif weathering and cracking of surface layers in the oldest parts of medieval mine depending on used mining method. Arch. Min. Sci., Vol. 61 (2016), No. 2, p. 381-395. DOI 10.1515/amsc-2016-0028.

Lyubushin Jr., A.A. (2001). Multidimensional wavelet analysis of geophysical monitoring time. Izvestiya, Physics of the Solid Earth, Series A., Vol. 37, No. 6, p. 474-483.

Lyubushin Jr., A.A. (2007). Interactive program Spectra_Analyzer for scalar time series data mining. http://alexeylyubushin.narod.ru/Software_for_Point_Processes_Periodicity_and_Scalar_Time_Series_Dat a_Mining.pdf

Lyubushin Jr., A.A, Kaláb, Z. and Lednická, M. (2012). Geomechanical time series and its singularity spectrum analysis. Acta Geod Geophys Hung, Vol. 47(1), p. 69-77.

Lyubushin Jr., A.A, Kaláb, Z., Lednická, M. and Haggag, H.M. (2013). Discrimination of earthquakes and explosions using multi-fractal singularity spectrums properties. J Seismol, Vol. 17(3), p. 975-983.

Lyubushin Jr., A.A, Kaláb, Z. and Lednická, M. (2014). Statistical properties of seismic noise measured in underground spaces during seismic swarm. Acta Geodaetica et Geophysica, Vol. 49, No. 2, p. 209-224.

Pandula, B., Kondela, J. and Tometz, L. (2007). The results of measurements of induced seismic vibration at the Zemplínska Široká and Malý Horeš localities. Acta Montanistica Slovaca, Vol. 12 (2007), No. 1, p. 2936. /in Slovak/ https://actamont.tuke.sk/pdf/2007/n1/6pandula.pdf

Pijush, P. R. (2009). Rock blasting: Effects and operations. A.A. Balkema Publishers.

Pratt, H.R., Hustrulid, W.A. and Stephenson, D. E. (1978). Earthquake damage to underground facilities. Savannah River Laboratory Report, DP-1513, p. 20-25.

Serati, M. and Moosavi, M. (2010). Analysis of influencing factors in response spectrum of underground structures using numerical method. In: Rock stress and earthquakes. Proceedings of the Fifth International Symposium on In-situ Rock Stress and Earthquakes, Beijing, China, p. 579-583.

Telesca, L., Lovallo, M., Kaláb, Z. and Lednická, M. (2011). Fluctuation analysis of the time dynamics of laser distance data measured in the medieval Jeroným Mine (Czech Republic). Physica A (2011), Elsevier, p. 3551-3557. DOI: 10.1016/j.physa.2011.04

Tomíček, R. (2011). Historical and cultural review of the Jeroným Mine. International Journal of Exploration Geophysics, Remote Sensing and Environment (EGRSE), Vol. XVIII, No. 1, p. 14-22. /in Czech/ https://caag.cz/egrse/2011-1/clanek_02.pdf

Udías, A. and Buforn, E. (2017). Principles of seismology. Cambridge University Press.

Varnusfaderani, M.G., Golshani, A. and Nemati, R. (2015). Behavior of circular tunnels crossing active faults. Acta Geodyn. Geomater., Vol. 12, No. 4 (180), p. 363-376. doi: 10.13168/AGG.2015.0039 